\title{
Oestrogen metabolism and excretion in liver disease
}

\author{
J. B. BROWN ${ }^{1}$, G. P. CREAN, AND JEAN GINSBURG ${ }^{2}$ \\ From the Clinical Endocrinology Research Unit \\ (Medical Research Council), and the Gastro-intestinal Unit, \\ Western General Hospital, University of Edinburgh, \\ and the Department of Medicine, St. Thomas's Hospital, London
}

EDITORIAL SYNOPSIS Raised urinary oestrogen excretion was noted in 16 men and women with liver disease. The study suggests that the increased output of urinary oestrogens was usually due to increased secretion rates of the primary oestrogenic hormones rather than to impaired oestrogen metabolism by the liver.

Numerous workers have reported a raised output of urinary oestrogens in men and women with various types of liver disease. Glass, Edmonson, and Soll (1940), Rupp, Cantarow, Rakoff, and Paschkis (1951), Pincus, Rakoff, Cohen, and Tumen (1951), and Dohan, Richardson, Bluemle, and György (1952), using bioassay methods, all found in approximately $48 \%$ of the patients studied values which usually were less than twice the normal maximum but occasionally were as high as seven times the normal. Later workers, using colorimetric measurements, have investigated a smaller number of patients and have found raised values in only approximately $20 \%$ of the cases, and no value has exceeded twice the normal maximum (Cameron, 1957; Lyngbye and Mogensen, 1961). This raised output has been attributed to impaired metabolism by the diseased liver but evidence for this concept has been conflicting. Glass, Edmonson, and Soll (1944) administered oestrone and oestradiol to three patients with liver disease and recovered $83-86 \%$ of the biological activity of the administered dose in the urine whereas values of $10 \%$ would have been expected for normal individuals. On the other hand, Dohan et al. (1952) and Cameron (1957) measured endogenous urinary oestriol, oestrone, and oestradiol separately and found that the major urinary oestrogen in liver disease is often oestriol, which is the least biologically active of the three. After the administration of oestrone, oestradiol, or their esters to patients with liver disease, Støa, Bassøe, and Emberland (1958), in a study of five cases, found a decreased recovery as the three oestrogens in two and an increased recovery in one, and Lyngbye and

\footnotetext{
'Present address: Royal Women's Hospital, Melbourne, Australia.

${ }^{2}$ Present address: Department of Obstetrics, Charing Cross Hospital Medical School, I.ondon.
}

Mogensen (1961) in five cases found normal overall recoveries but in two the recovery as oestradiol was increased at the expense of the oestriol. The metabolic pattern described by the different workers has therefore not been consistent.

During the past five years we have had the opportunity of studying oestrogen output and metabolism in a group of patients with various types of liver disease. Although the results in general conform with those already reported, two patients with particularly high oestrogen outputs were encountered, and these are presented with our general findings, since similar values have not previously been reported using chemical assay methods.

\section{THE INVESTIGATION}

OESTROGEN MEASUREMENT The urinary excretion of oestriol, oestrone, and oestradiol was measured by the method of Brown (1955) as modified by Brown, Bulbrook, and Greenwood (1957). The urine specimens from London were collected in polythene bottles, deep frozen, packed in straw, and despatched to Edinburgh for assay.

The endogenous oestrogen output was measured on at least two 24- or 48-hour urine collections. Metabolic experiments were performed by administering oestradiol, $2.5 \mathrm{mg}$. intramuscularly in olive oil, and determining the increased output of urinary oestriol, oestrone, and oestradiol during the next six consecutive days. The results of these measurements are summarized in the Table. No correction was made for losses of oestrogens occurring in the assay procedure.

PATIENTS Studies were made on 13 men and three women with liver disease. Their age, sex, and type and severity of liver disease are listed in the Table. Stigmata of chronic liver disease (clubbing of the fingers, spider naevi, and palmar erythema) were noted in cases $1,8,10$, 11, and 12. Endocrine changes were also observed as follows: gynaecomastia (cases 1 and 4), testicular atrophy 
TABLE

URINARY OUTPUT OF ENDOGENOUS OESTROGENS AND RECOVERY OF ADMINISTERED OESTRADIOL IN PATIENTS WITH LIVER DISEASE

Case Age Sex Clinical Particulars

\begin{tabular}{|c|c|c|c|c|c|c|c|c|}
\hline \multirow[t]{2}{*}{ Biliuria } & \multicolumn{4}{|c|}{$\begin{array}{l}\text { Endogenous Oestrogens } \\
\text { ( } \mu \mathrm{g} .124 \mathrm{hr} . \text { urine })\end{array}$} & \multicolumn{4}{|c|}{$\begin{array}{l}\text { Exogenous Oestrogens } \\
(\% \text { of dose recovered })\end{array}$} \\
\hline & Oestriol & Oestrone & Oestradiol & Total & Oestriol & Oestrone & Oestradiol & Total \\
\hline+ & 326 & 55 & 15 & 396 & & & & \\
\hline+ & 103 & $13 \cdot 6$ & $5 \cdot 6$ & 122 & & & & \\
\hline+ & $2 \cdot 6$ & $3 \cdot 2$ & 0 & 5.8 & & & & \\
\hline+ & $5 \cdot 7$ & $2 \cdot 2$ & 1.7 & $9 \cdot 6$ & & & & \\
\hline+ & $3 \cdot 8$ & $2 \cdot 9$ & 1.6 & $8 \cdot 3$ & & & & \\
\hline+ & $6 \cdot 8$ & $15 \cdot 8$ & 0.9 & $23 \cdot 5$ & & & & \\
\hline - & $14 \cdot 5$ & $2 \cdot 2$ & 1 & $16 \cdot 7^{1}$ & $19 \cdot 0$ & 1.9 & 0.8 & $21 \cdot 7$ \\
\hline - & $18 \cdot 5$ & 1.9 & 1 & $20 \cdot 4^{1}$ & $11 \cdot 1$ & 1.0 & 1.4 & $13 \cdot 5$ \\
\hline - & $18 \cdot 6$ & 3.0 & $1 \cdot 3$ & $22 \cdot 9$ & $6 \cdot 7$ & $2 \cdot 8$ & 1.5 & $11 \cdot 0$ \\
\hline+ & $19 \cdot 7$ & $10 \cdot 8$ & 1.8 & $32 \cdot 3$ & $9 \cdot 8$ & $7 \cdot 2$ & $3 \cdot 7$ & $20 \cdot 7$ \\
\hline+ & 1.6 & $57 \cdot 6$ & $7 \cdot 5$ & $66 \cdot 7$ & & & & \\
\hline+ & $14 \cdot 7$ & $6 \cdot 1$ & 0.4 & $21 \cdot 2$ & & & & \\
\hline+ & $10 \cdot 0$ & $8 \cdot 8$ & 0.9 & $19 \cdot 7$ & $4 \cdot 3$ & $5 \cdot 6$ & $2 \cdot 3$ & $12 \cdot 2$ \\
\hline+ & $18 \cdot 5$ & $3 \cdot 6$ & 0.3 & $22 \cdot 4$ & $9 \cdot 4$ & 1.5 & 1.2 & $12 \cdot 1$ \\
\hline- & 6.6 & $8 \cdot 7$ & $2 \cdot 5$ & $17 \cdot 8$ & $3 \cdot 6$ & 4.0 & $2 \cdot 2$ & $9 \cdot 8$ \\
\hline+ & $11 \cdot 2$ & $4 \cdot 1$ & 0.7 & $16 \cdot 0$ & 2.5 & $1 \cdot 1$ & $0 \cdot 6$ & $4 \cdot 2$ \\
\hline- & $9 \cdot 5$ & $3 \cdot 4$ & $0 \cdot 3$ & $13 \cdot 2$ & $15 \cdot 6$ & $4 \cdot 3$ & 2.9 & $22 \cdot 8$ \\
\hline
\end{tabular}

\begin{tabular}{llll}
\hline & 40 & M & $\begin{array}{l}\text { Alcoholic cirrhosis } \\
\text { Terminal Day 1 } \\
\text { Day 2 }\end{array}$ \\
\hline & & &
\end{tabular}

$\begin{array}{llll}2 & 57 & \text { M } & \text { Severe, Nov. } 1960\end{array}$

Deteriorating, Feb. 1961

Deteriorating, Nov. 1961

$\begin{array}{llll}3 & 65 & F & \text { Terminal studied after }\end{array}$

portocaval shunt

$\begin{array}{llll}4 & 53 & M & \text { Mild }\end{array}$

$\begin{array}{llll}5 & 61 & \text { M } & \text { Mild } \\ 6 & 52 & \text { M } & \text { Mild }\end{array}$

Post-hepatitic cirrhosis

$\begin{array}{llll}7 & 35 & \text { M } & \text { Severe, Oct. } 1957\end{array}$

$\begin{array}{llll}8 & 47 & \text { M } & \begin{array}{l}\text { Terminal, Feb. } 1958 \\ \text { Severe }\end{array}\end{array}$

$9 \begin{array}{llll}89 & \text { F } & \text { Severe }\end{array}$

Cryptogenic cirrhosis

$\begin{array}{llll}10 & 44 & M & \text { Severe }\end{array}$

$\begin{array}{llll}11 & 48 & M & \text { Moderate, hepatoma }\end{array}$

$12 \quad 67 \quad M \quad$ Moderate

$13 \quad 53 \quad M \quad$ Mild

$1450 \quad M \quad$ Carcinomatosis of liver

$33.7 \quad 3.2$

$1 \cdot 7$

$38 \cdot 6$

Obstructive jaundice

$15 \quad 60 \quad \mathrm{~F} \quad$ Carcinoma of pancreas

$16 \quad 64 \quad M \quad$ Stone with biliary cirrhosis

Normal Values

Men (24) ${ }^{2}$ (Ginsburg and Brown, 1961)

Post-menopausal women (10) (Brown, Kellar, and Matthew (1959)

\begin{tabular}{|c|c|c|c|c|}
\hline $\begin{array}{l}\text { Range } \\
\text { Mean } \pm \text { S.D. }\end{array}$ & $\begin{array}{l}1.9-11 \cdot 1 \\
4 \cdot 7 \pm 2 \cdot 7\end{array}$ & $\begin{array}{l}2 \cdot 8-7 \cdot 9 \\
5 \cdot 1 \pm 1 \cdot 4\end{array}$ & $\begin{array}{l}0-2 \cdot 8 \\
1 \cdot 3 \pm 0 \cdot 7\end{array}$ & $\begin{array}{l}7 \cdot 2-19 \cdot 6 \\
11 \cdot 1 \pm 3 \cdot 1\end{array}$ \\
\hline $\begin{array}{l}\text { Range } \\
\text { Mean }\end{array}$ & $\begin{array}{l}2 \cdot 2-7 \cdot 5 \\
3 \cdot 9\end{array}$ & $\begin{array}{l}0 \cdot 3-2 \cdot 4 \\
1 \cdot 3\end{array}$ & $\begin{array}{l}0-1 \cdot 4 \\
0.3\end{array}$ & $\begin{array}{l}3 \cdot 2-9 \cdot 0 \\
5 \cdot 5\end{array}$ \\
\hline
\end{tabular}

Men and post-menopausal women (6) (Brown, 1957)

\section{Range}

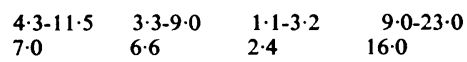

Mild = no clinical manifestations of liver disease, diagnosis made by liver biopsy

Moderate $=$ clinical evidence for liver disease but without severe complications.

Severe $=$ severe complications of liver disease, including portal hypertension, ascites, and neuro-psychiatric manifestations.

Terminal $=$ dying within one week with severe complications but not comatosed at the time of study.

'Implies interference in the oestradiol measurements.

${ }^{2}$ No. of cases.

(cases 4, 5, and 7), and amenorrhoea (case 9). Biochemical tests of liver function were performed in many instances and the results in general confirmed the diagnosis made on clinical and histological evidence. Further details of the two patients with particularly abnormal values for urinary oestrogens were as follows.

Case 1 This man was a chronic alcoholic. Evidence of cirrhosis of the liver was noted in 1953 at the age of 36 years. Right gynaecomastia was observed in 1956, and in 1957 he was admitted in impending hepatic failure with jaundice, haematemesis, oedema, ascites, neuropsychiatric manifestations, clubbing of the fingers, and spider naevi. He was treated by splenectomy on 19 September 1957, and later required a laparotomy for obstruction and peritonitis on 24 September. Urines were collected for assay on 28 and 29 September. He lapsed into hepatic coma and died on 2 October.

Case 7 This man contracted infectious hepatitis in 1944 at the age of 22 years. This was followed by slowly progressive cirrhosis with fluctuating jaundice and oedema. In October 1957, when the first study was made, the patient was suffering from jaundice (serum bilirubin $2.4 \mathrm{mg}$. \%), oedema, and neuro-psychiatric manifestations. He deterioriated rapidly and in February 1958, when the second study was made, he was deeply jaundiced (serum bilirubin $27.5 \mathrm{mg}$. \%). He lapsed into coma two days after the study and died two days after this. At necropsy, the liver showed gross post-necrotic cirrhosis, the testes showed diminished spermatogenesis but the pituitary, adrenals, thyroid, and prostate appeared normal.

\section{RESULTS}

The results of the investigation are summarized in the Table. In some patients there was interference in the oestradiol measurements as indicated by negative values following spectrophotometric 
correction, and in these cases the true 'total' figures were probably slightly higher than those given.

Grossly abnormal oestrogen figures were found in the two patients, cases 1 and 7. Case 1 was excreting twenty times the normal maximum on the second day; in both instances the output of all three oestrogens was elevated and oestriol was the major oestrogen. Case 7, in October 1957, had a moderately increased total output, and oestriol was the major oestrogen; the recovery of administered oestradiol was normal, the ratios of the three oestrogens recovered resembling those of the endogenous output. In February 1958, the total excretion had increased to more than three times the normal maximum, and, of this, the major portion was oestrone with practically no oestriol. Of the remaining 14 patients, seven (cases 3, 5, 6, 8, 9, 10, 14) were excreting 'total' amounts of oestrogens which were one to two times the maximum figures found in normal men and post-menopausal women. In six of these the increase was mainly in the output of oestriol, and in one only (case 3 ) was it confined to the oestrone.

Metabolic experiments were performed in nine patients (cases $4,5,6,7,9,10,11,12,13$ ). In eight of these, who included four of the patients with a higher endogenous output than normal, the total recovery was within the normal range, the mean $(15.5 \%)$ comparing with the mean figures of $16.0 \%$ and $14.7 \%$ reported by Brown $(1957,1958)$. The ratios of the three oestrogens recovered resembled those of the endogenous output, and in four patients (cases $4,5,10,13$ ) the proportion of oestriol relative to oestrone and oestradiol was greater than normal; in three of the cases (nos. 5, 10, 13) the recovery as oestradiol approached or exceeded the amount in the oestrone fraction, whereas in normals urinary oestradiol is generally less than half the oestrone. An abnormal 'total' recovery was found in only one patient (case 12), the figure being less than half the normal minimum, and in this case again oestriol was the major metabolite.

\section{DISCUSSION}

The results obtained here demonstrate most of the abnormalities in oestrogen output and metabolism which have been reported in liver disease. Thus, the occasional very high values previously obtained only by bioassay methods have now been demonstrated by a chemical assay procedure. The proportion of patients $(56 \%)$ with an elevated excretion of urinary oestrogens is higher than in any other group previously reported, a finding which is probably the result of selecting individuals who were most likely to show abnormalities, such as those four with severe complications and the three in terminal liver failure. As shown by Dohan et al. (1952) and Cameron (1957) the proportion of oestriol to the other endogenous oestrogens excreted was higher than normal in many patients, indicating that metabolism to this oestrogen is often enhanced in liver disease. However, in two instances (cases 3,7 ) the increase was confined to the oestrone fraction, as in the case reported by Lyngbye and Mogensen (1961). In the metabolism experiments, the overall recovery of administered oestradiol as urinary oestriol, oestrone, and oestradiol, was usually normal but occasionally low, as reported by Støa et al. (1958) and Lyngbye and Mogensen (1961): no high recoveries similar to those reported by Glass et al. (1944) were obtained. The ratio of oestriol to other oestrogens recovered was usually higher than normal, indicating an increased conversion, but such a finding is not confined to liver disease and has been reported in other diseases, such as breast cancer and coronary disease (Brown, 1958; Bauld, Givner, and Milne, 1957). Occasionally the ratio of oestradiol to oestrone was increased, as was demonstrated by Lyngbye and Mogensen (1961).

The two patients with particularly abnormal osetrogen levels merit special discussion. During his first investigation, case 7 was excreting oestriol, oestrone, and oestradiol in amounts which were greater than normal but within the range found in the majority of patients with liver disease. At this time, the overall recovery of administered oestradiol was normal and oestriol was the major metabolite. The picture had changed markedly four months later, when the patient was in terminal liver failure: the overall oestrogen output had increased, oestrone was the major urinary oestrogen, and the output of oestriol had virtually ceased. This indicated that the capacity of the liver to convert oestrone to oestriol had almost been abolished at this extreme stage of the disease. If the determination had been made by bioassay, the high oestrone output would have registered as a markedly increased output of oestrogenic activity. This was the only case in the series which provided evidence that metabolism of oestradiol and oestrone to oestriol may be impaired in liver disease. Case 1, with the highest oestrogen output encountered, was also in terminal liver failure when he was studied. However, in this case, all three of the oestrogen fractions were markedly elevated with oestriol predominating as the major metabolite. There was therefore no evidence in this case of impaired oestrogen metabolism by the liver. This patient's history was complicated by the fact that splenectomy and then an exploratory laparotomy had been performed several days before the study, and the high but falling oestrogen levels might have been caused by the adrenal responses to 
the two operations. However, these were exceptionally high levels, and beyond the response obtained by maximum stimulation of the adrenals with corticotrophin (Brown, Falconer, and Strong, 1959). No correlation could be demonstrated between abnormalities in oestrogen output and the severity of the liver disease as judged by clinical, histological, or biochemical findings. Although the abnormalities tended to be more common and more marked among those patients who were in the terminal stages of the disease, they also occurred in some of the mild cases of cirrhosis. The suggestion has frequently been made that various stigmata of liver disease, such as spider naevi and palmar erythema, and some of the endocrine changes such as gynaecomastia, are caused by raised oestrogen levels (Bean, 1959). In the present series, no such direct connexion could be demonstrated, a finding which is in agreement with that of Cameron (1957).

The metabolism experiments show that the raised urinary outputs of endogenous oestrogens found in liver disease are due in most instances to raised secretion rates of the primary oestrogenic hormone. The finding that the ratio of oestriol to oestrone and oestradiol in the urine is usually greater than normal shows that the diseased liver may actually have an increased capacity for metabolizing oestradiol and oestrone to oestriol. These experiments, however, provide no information concerning impairment or otherwise of the other metabolic pathways. Further investigation is obviously required to determine the source of the increased output of oestrogens. Raised urinary oestrogen levels have also been reported in hypertrophic pulmonary osteoarthropathy associated with bronchial carcinoma (Ginsburg and Brown, 1961) where there was no evidence of liver disease and no demonstrable abnormality of oestrogen metabolism. It is possible that the sources of the abnormal amounts of oestrogens are the same in the two disorders.

\section{SUMMARY}

Raised urinary oestrogen excretion was found in nine of 16 men and women with liver disease. The increased values were generally less than twice the normal maximum but one patient was excreting twenty times the normal maximum. The major urinary oestrogen was usually oestriol but occasionally it was oestrone.

The overall recovery of administered oestradiol as urinary oestriol, oestrone, and oestradiol was usually within the normal range but occasionally it was lower than normal. Increased recoveries were not observed. The major urinaty metabolite was usually oestriol but occasionally it was oestrone. These results indicate that, with one possible exception, the increased output of urinary oestrogens was due to increased secretion rates of the primary oestrogenic hormone rather than to impaired oestrogen metabolism by the liver.

Abnormalities in oestrogen output were most marked and common in terminal liver failure but they also occurred in mild cirrhosis.

These findings are in agreement with many already published using either bioassay or chemical techniques.

We wish to thank Dr. W. I. Card, Dr. W. Sircus, and Dr. R. W. D. Turner for access to their patients, and Mrs. Janet Blair and Miss Wilma McGillivray for technical assistance with the analyses. The endowment fund of St. Thomas's Hospital defrayed some of the expenses in sending specimens from London.

\section{REFERENCES}

Bauld, W. S., Givner, M. L., and Milne, I. G. (1957). Abnormality of estrogen metabolism in human subjects with myocardial infarction. Canad. J. Biochem., 35, 1277-88.

Bean, W. B. (1959). Vascular Spiders and Related Lesions of the Skin. Blackwells, Oxford.

Brown, J. B. (1955). A chemical method for the determination of oestriol, oestrone and oestradiol in human urine. Biochem. J., 60, 185-193.

, Kellar, R., and Matthew, G. D. (1959). Preliminary observations on urinary oestrogen excretion in certain gynaecological disorders. J. Obstet. Gynaec. Brit. Emp., 66, 177-211.

(1957). The relationship between urinary oestrogens and oestrogens produced in the body. $J$. Endocr., 16, 202-212.

, (1958). Urinary oestrogen excretion in the study of mammary cancer. In Endocrine Aspects of Breast Cancer, edited by A. R. Currie, pp. 197-213. Livingstone, Edinburgh and London.

- Bulbrook, R. D., and Greenwood, F. C. (1957). An additional purification step for a method for estimating oestriol, oestrone and oestradiol-17 $\beta$ in human urine. J. Endocr., 16, 49-56.

- Falconer, C. W. A., and Strong, J. A. (1959). Urinary oestrogens of adrenal origin in women with breast cancer. J. Endocr., 19, $52-63$.

Cameron, C. B. (1957). Urinary excretion of oestrone, oestradiol-17 $\beta$ and oestriol in patients with chronic liver damage. Ibid., 15, 199-205.

Dohan, F. C., Richardson, E. M., Bluemle, L. W., Jr. and György, P. (1952). Hormone excretion in liver disease. J. clin. Invest., 31, 481-498.

Ginsburg, J., and Brown, J. B. (1961). Increased oestrogen excretion in hypertrophic pulmonary osteoarthropathy. Lancet, 2, 1274-76.

Glass, S. J., Edmondson, H. A., and Soll, S. N. (1940). Sex hormone changes associated with liver disease. Endocrinology, 27, 748-752.

, - (1944). Excretion of estrogen after the injection of estradiol and estrone into men with cirrhosis of the liver. J. clin. Endocr., 4, 54-57.

Lyngbye, J., and Mogensen, E. F. (1961). Oestrogen metabolism in women with cirrhosis of the liver. Acta endocr. (Kbh.), 36, 350-360.

Pincus, I. J., Rakoff, A. E., Cohn, E. M., and Tumen, H. J. (1951). Hormonal studies in patients with chronic liver disease. Gastroenterology, 19, 735-754.

Rupp, J., Cantarow, A., Rakoff, A. E., and Paschkis, K. E. (1951) Hormone excretion in liver disease and in gynecomastia. J. clin. Endocr., 11, 688-699.

Støa, K. F., Bassøe, H. H., and Emberland, R. (1958). Oestrogen metabolism in normal and pathological liver function as studied by chromatographic urine analysis. Acta endocr. (Kbh.), 28, 357-365. 